\title{
CHEMICAL PLANT MANAGEMENT
}

\begin{abstract}
S a contribution to National Productivity Year, the North-Western Branch of the Institution of Chemical Engineers and the Manchester Section of Chemical Industry arranged a symposium in Manchester on December 11. The theme of the symposium was the utilization of resources in relation to chemical plant management. The chairman was R. J. Kingsley, joint managing director of Lankro Chemicals, Ltd.
\end{abstract}

Introducing the function of plant management, V. Murtagh, of Joseph Crosfield, Ltd., reviewed some of the changes which have occurred in the chemical industry and indicated the kind of structure which has emerged and which has indirectly led to these changes. In 1935 the net output figure (the value added to purchased materials) was recorded at $£ 35$ million. By 1946 this had reached $£ 95$ million. By 1960 net output was $£ 736$ million. Total turnover in the industry practically doubled. between the years 1955 and 1960 alone. A considerable portion of this growth is due to new products developed and introduced within the past twenty years. The growth of the petro-chemicals industry, which doubled in size between 1955 and 1958, and the growth of the man-made fibres industry provide two examples.

This is as it should be. The chemical industry is a science-based industry. Its existence depends on the application of scientific techniques and it employs managers who are capable of recognizing and creating opportunities for profitable and speedy commercial development of these techniques. Parallel with the growth of the industry has been the growth of research and development activities. Although no accurate figures are available for the pre-war, say 1935, era, it is doubtful if expenditure exceeded $£ 1$ million per annum. By 1946 the industry was spending at the rate of $£ 8.5$ million per annum. This had doubled by 1955 . By 1955 expenditure rose to $£ 35$ million and present estimates for 1962 are in the region of $£ 45$ million per annum. These figures exclude capital spending and depreciation charges. Nor is this growth confined to the large firm. While there are now twice as many firms with research and development establishments as before the Second World War, much of the expansion is in the medium- and small-sized firms. There is an interesting relationship between research and development expenditure and growth. The five fastest growing chemical firms either in terms of fixed assets or in terms of profits were those firms with the highest research and development ratios. The five slowest growing firms were those with the lowest ratios.

Of the 1960 research and development expenditure of $£ 36$ million, $£ 12.5$ million was devoted to basic research. This is a much higher proportion than for industry in general, and is slightly higher than the proportion of 11 per cent now quoted for the American chemical industry. Twenty-nine per cent of the total research and development expenditure is spent in applied research and development of new products and new processes. The biggest amount (37 per cent, or nearly $£ 15$ million) is devoted to the development of existing processes, either to improve the process or the product, or to utilize different raw materials. Practically two-thirds of this expenditure is devoted to minor rather than major improvements. This reflects the high significance of the processing cost in chemical operations on profit margins. Twenty-one per cent of research and development expenditure is the provision of technical services. The plant manager of bygone years, with the help, perhaps, of the chief chemist, probably provided most of the technical service that the sales department required. To-day this is an activity in its own right.

Other changes in the industry are significant. Plants are generally larger. The processes are generally continuous rather than batch. In corrosion-resistant materials they cost many times their pre-war equivalent to build and maintain. This aggravates the problem of determining the right size of plant for new products. It extends the semi-works scale of the experimental period in the development of new products and it tends to delay in approving capital expenditure for major projects. Plants are much more highly instrumented. New skills are required on the part of managers, supervisors and operators. Training of operators is much more essential than it was in the past, and this training has to be provided and guided by the industry itself. Against this background of change, the plant management function is subject to two real pressures: (1) With existing products the pressure is to improve quality, or service, or cost, and since the ex works cost of most chemicals has by far the biggest single effect on profit margins, this will always remain. (2) With new products, the pressure on development will apply to the work to be done in filling the gap between the pilotplant scale and eventual full-scale production. To meet these pressures, the plant manager is charged with managing people, with manipulating, controlling, methods, processes, plant and machinery. 'Road blocks' in the way of more efficient operation can be found just as often in the various levels of management as they can on the shop floor. However, Murtagh emphasized that, in the National Productivity Year, in utilizing human resources it would be a mistake to become excessively preoccupied. with the problem of motivating the man on the shop floor.

This theme was taken up by A. F. Shaw, of Associated Industrial Consultants, who indicated, however, that the best return from middle management and staff will not be obtained by consideration of motivation, but by provision of direction, leadership, encouragement and control. F. J. Neale, of Urwick, Orr and Partners, did examine the motivation of shop-floor workers and suggested the need for radical reform in attitudes towards wage payments. At present, many shop-floor jobs are considered on either a daily or weekly basis, and if bonus is paid they are linked to this period. Where physical work is concerned this may be sufficient, but with more mechanization and automation, this time-scale is too short. Jobs should be viewed in longer terms, say, one month, three months, six months, twelve months and two years. The worth of the jobs should be calculated in relation to this time span and the person paid accordingly, that is, a twelve-month job would have guaranteed wagos for that period of time at a set rate per week. A review would take place overy twelve months and the worth of that job evaluated either up or down for the next twelve months. This would apply to other timescales. This type of approach has cortain advantages and disadvantages. The disadvantages are that those jobs with a longer time-span may change considerably before they are reviewed, and, if the job disappears early in the period, the employer is out of pocket through his guarantee of wages for the period. The advantages are easier wage calculations and easier measurement of the jobs. Wages remain constant and do not havo violent fluctuations.

C. MeDermott, of Coalite and Chemical Products, Ltd., suggested that, in addition to a sound basic pay system, greater effectiveness can only be secured from work- 
people where there is stability of employment, good communications and working conditions and effective education and training. The training and re-training of operators was discussed by C. V. Kettle, of Lankro Chemicals, Ltd., who emphasized the trend towards less operators and more supervising, the supervision of plant rather than men. Among operators, although new and increased skills are necessary, 'knowledge' is becoming relatively more important than traditional 'skills'. There is a need for knowing 'why' as well as 'how'. Decisionmaking is increasing in importance at oporative level. It is necessary for early recognition of faults and ability to determine the cause. Operators now need to be more adaptable and, at the same time, to move out of the 'arts' class of 'sniffing', 'tasting' and 'feeling' to the use of more sophisticated controls. No longer can he afford to have men 'picking up' tho job by working alongside experienced operators who may be unwilling or incapable of teaching, and who may show the newcomer short cuts without warning of the hazards.

Training of new employees and re-training of presentday operatives can help to overcome such problems. To match the pace of change, operators may need re-training four or five times in their working lifo as opposed to the 'once for all' training. The basic approach should be a methodical analysis of the job to discover: (1) its purposo; (2) the qualitios, quantities and uses of the product; (3) knowlodge of the plant, equipment and raw materials; (4) any special techniques involved; (5) safety factors concerned and attitudes required; (6) faults which may occur at infrequent intervals. From such an analysis an instruction manual can be prepared, the tasks being divided into suitable portions and consideration given to methods of presentation. In presenting training, interest and a sense of worth-whileness must be created at the earliest stage. Instruction should be varied, that is, interwoven practical activities with classroom instruction and discussion. The pace of instruction should be adjusted to the capacity of the learner and must be given in reasonably sized portions which can be practised and shown to be understood before the next portion is tackled. Portions are then combined until eventually the whole job is being performed at the required standard.

There should be a specific person responsible for instructing. Such a person could be selected and developed for this specialist function. In-training of oporators can often be effectively supported by external courses organized by technical colleges, industrial safety training centres, manufacturers of equipment, employors' associations, and the Ministry of Labour. In the next 5-10 years 'automated teaching' will be playing a substantial part in the training of operators.

Three other papers dealt with the optimum utilization of physical resources in chemical plant. G. W. Sears, of Shell Chemical Co., Ltd., discussed the role of linear programming and its significance in planning the production of large-scale continuous processes. The use of linear programming was also described by A. Battersby, of the Work Study School at Cranfield, who, by means of a case study, indicated how a linear programming matrix of the plant could yield information which could be useful in planning not only the manufacturing process but also the plant and its products. Finally, J. Roughley, of Peter Spence and Sons, Ltd., considered the role of maintenance planning in relation to production and indicated that objective maintenance study is a major factor in total manufacturing oconomy.

The value of the symposium was reflected by the large size of the audience and the worth-whileness of the discussions.

T. H. HawkINS

\section{APPLICATION OF SCIENCE AND TECHNOLOGY FOR THE BENEFIT OF THE LESS-DEVELOPED AREAS}

$\mathrm{T}$ HE papers prepared by the United States for the United Nations Conferonce on the Application of Science and Technology for the Benefit of the Lessdevelopod Areas in February 1963 have now been published by the United States Agency for International Development in a series of twelve volumes*. These represont an impressive contribution to the growing body of literature in the United States on the problems and processos of development, and on the experience and techniques which could assist those engaged in planning and executing development. The various sections are generally well supplied with reforences, and there are cross-reforences from one volume to another when particular papers are of intorest in more than ono context, while the Agency has issued as a companion volume to the sories a Selected Reading List which briefly describes some 1,200 books and articles dealing with this field recently published in the United States. Somo of the

* Science, Technology and Development: United States Papers prepared for the United Nations Conference on the Application of Science and Technology for the Benofit of the Less Developed Areas. Vol. 1: Natural Re sources-Energy, Water and River Basin Development. Pp. ix +378 . 1.25 dollars. Vol. 2: Natural Resources-Mineral and Mining; Mapping and Geodetic Control. Pp. vii + 355. 1 dollar. Vol. 3: Agriculture. Pp. $\mathrm{x}+262$ 75 cents. Vol. 4: Industrial Development. Pp. ix +90.55 cerits. Vol. 5 Transportation. Pp ix +165.50 cents. Vol. $6:$ Health and Nutrition. Pp $\mathrm{vi}+196.60$ cents. Vol. 7 . Social Problems of Development and Vrbanisation. Pp. Ix +89 . 35 cents. Vol. 8: Organisation, Planning and Programming for Economic Development. Pp. $\mathrm{x}+144.45$ conts. Vol. 9: Screntific and Tech nolagical Policy, Planning and Organisation. Pp. xi+60. 30 cents. Vol. 10 : International Co-operation and Problems of Transfer and Adaptation. Pp.
vili +63 . 30 cents. Vol. $11:$ Human Resources-Training of Scientific and Technicat Personnel. Pp. xii +204. 60 cents. Vol. 12: Communications. Ppo2-63.) articles represent collaboration between American specialists and their professional colloagues in other countries: all the authors wore chosen as recognized experts and soholars in their fields and they includo, for example, such well-known names as those of Dr. J. R. Killian, Dr. A. V. Astin and Prof. H. D. Lasswell.

It is impossible here to do more than indicate the scope of the whole series by noting some of the sections in the various volumes. Vol. 1, dealing with energy, water and river basin development, has sections on: problems of electrification; mining and efficiency in use of coal; achieving productive capacity of oil; nuclear energy; economics of choice among alternative energy sources; water and river basin devolopment, including low-cost waste treatment and desalination. Vol. 2, on minerals and mining, has sections on: the role of government; the co-operative approach; planning and staffing for mineral development; exploration techniques; extracting and processing the ore; and on mapping and goodotic control. Vol. 3, on agriculturo, includes sections on institutional and social aspects of agricultural develop. ment; improvements in levels of nutrition; development of land, and water resources; crop production and protection; animal health and breeding; forestry and fishery resources and production. Vol. 4, on industrial dovelopment, includes sections on: approaches to in dustrial development; essential programmes and key institutes; industrial analyses; and product analyses.

The papers presented in Vol. 5 deal with transportation. covering transport by rosd, rail and water, the movement 